\title{
CORPOS ABJETOS EM THE NORMAL HEART: A AIDS EM TELA
}

\section{P. N. CHAVES ${ }^{1 *}$ e T. P. NÓBREGA ${ }^{2}$}

${ }^{1}$ UFRN. Mestranda pelo Programa de Pós-Graduação em Educação Física. Bolsista CAPES.

${ }^{2}$ UFRN. Programa de Pós-Graduação em Educação Física. Bolsista CAPES de Estágio Sênior - École Normale Supérieure/Paris.

paulinha_nunes3@hotmail.com

Resenha submetida em maio/2015 e aceito em outubro/2015

DOI: $10.15628 /$ holos. 2015.3043

\section{RESUMO}

Essa resenha tem como objetivo apresentar o filme The Normal Heart (2014), e tecer considerações sobre o surgimento da epidemia da Aids e suas interlocuções com o corpo, a abjeção, a identidade sexual e a tensão existente entre o controle e a liberação sexual a partir das lentes da obra cinematográfica em evidência que historiciza a doença, atentando para os elementos cruciais que perpassaram a epidemia. Para tanto, nos ancoramos em uma compreensão da arte cinematográfica como linguagem que nos possibilita outras maneiras de enxergar o mundo, o corpo e os acontecimentos, bem como proporciona diversas formas de interpretação e criação de sentidos a partir das visibilidades e historicidades em tela.

PALAVRAS-CHAVE: Corpo, Aids, homossexualidade, cinema.

\section{ABJECTS BODIES IN THE NORMAL HEART: AIDS IN EVIDENCE}

\begin{abstract}
This review aims to present the film The Normal Heart (2014), and discuss about the emergence of AIDS epidemic, making a dialogue with the body, abjection, sexual identity and the tension between the control and sexual liberation, using this film in evidence that historicizes the disease, showing the crucial elements
\end{abstract}

that permeated and crossed the epidemic. We have a understanding of film as art and language that create new possibilities of comprehension, other ways of seeing the world, the body and the events, providing to us many ways of interpretation and creation of meanings from the visibility and histories in evidence on screen.

KEYWORDS: Body, Aids, homosexuality, cinema. 


\section{INTRODUÇÃO}

A historiografia do cinema nos adverte sobre a dificuldade do tratamento da temática da sexualidade nas películas, principalmente no que diz respeito às sexualidades dissidentes ou nãonormatizadas. A pluralidade sexual não foi característica presente nas representações e narrações cinematográficas, como nos confidencia Nazário (2007), imperando, muitas vezes, a ordem normativa com seus padrões de sujeitos moralmente "sadios". Ao centrarmos inicialmente a discussão da relação entre cinema e sexualidades não normatizadas, é importante acionar o autor supracitado para refletir que o cinema, durante muito tempo, apenas sugeria a existência da homossexualidade, perpassando por momentos nos quais deveria mostrar somente modelos de vida moral tido como corretos, sem dar visibilidade ao que era considerado pecado frente às leis divinas.

Os filmes, então, balizavam-se no padrão estético de uma sexualidade heteronormativa, e o desejo homossexual refugiou-se no cinema marginal e underground. Somente a partir da década de 70, a homossexualidade passou a transitar mais efetivamente nas películas, no entanto, ainda de forma secundária e estereotipada ligada à tragédia e à decadência, de forma que todas as telas de cinema anunciavam a impossibilidade de coexistência entre felicidade e homossexualidade, mostrando os destinos fatídicos e trágicos daqueles que viviam o amor "impróprio". Na atualidade, após todo o efeito provocado na indústria fílmica com o advento da AIDS, que proporcionou a retirada do caráter clandestino da homossexualidade, colocando-a em pauta, é possível falar de um vigoroso cinema gay, composto pelas mais diversas formatações e enredos (NAZÁRIO, 2007).

É nesse contexto de enredos cinematográficos que visibilizam a homossexualidade que desponta a película em tela nesse texto. The Normal Heart é um drama estadunidense lançado no ano de 2014 e dirigido por Ryan Murphy, que versa sobre cenário de abjeção para com o homossexual catalizado pela Aids. O filme visibiliza a emergência do "câncer gay" e a indiferença das autoridades governamentais para com a epidemia de alta letalidade que se alastrou nos Estados Unidos, acometendo, inicalmente, a comunidade homossexual masculina.

A produção pode ser considerada um marco para o cinema gay, primeiramente por nos oferecer um amor e um desejo homossexual sem véus e interdições, colocando na tela central olhares, sorrisos, gestos, beijos, carícias, sexos e atos que materializam a vivência do desejo gay por vezes escondido, difarçado e clandestino. Além disso, ao versar sobre o surgimento do "cancêr gay" nos Estados Unidos, seus primeiros momentos, sua capacidade de se espalhar rapidamente na comunidade gay e a organização dessa mesma comunidade dentro de uma esfera de tensão política, nos brinda com um panorama histórico, político, social e sexual da época que marcou profundamente a história da sexualidade e da homossexualidade, provocando tranformações que reverberam na forma de enxergar essas dimesões até os dias de hoje, dentre elas a associação entre homossexualidade e Aids.

Nessa direção, essa resenha tem como objetivo apresentar o filme The Normal Heart (2014), e tecer considerações sobre a epidemia da Aids e suas interlocuções com o corpo, a abjeção, a identidade sexual e a tensão existente entre o controle e a liberação sexual a partir das lentes da obra cinematográfica em tela que historiciza a doença, atentando para os elementos cruciais que 
perpassaram a epidemia, inclusive a negligência e indiferença fatal do governo dos Estados Unidos para com o surto.

Para tanto, nos ancoramos em uma compreensão da arte cinematográfica não apenas como simples ilustração ou representação da realidade, mas como linguagem que nos possibilita outras maneiras de enxergar o mundo, o corpo e os acontecimentos, bem como proporciona diversas formas de interpretação e criação de sentidos a partir das visibilidades em tela. Ao sermos atingidos pelas imagens do cinema, temos nosso olhar ampliado a partir destas em movimento, que nos fazem mergulhar em histórias, em um determinado espaço e tempo, e que tem muito a nos dizer sobre a experiência existencial e corpórea (LIMA NETO; NÓBREGA, 2014). No caso do filme aqui apresentado e analisado, voltamos nossa experiência do olhar no cinema para os corpos, que com seus gestos, atitudes, olhares, palavras, silêncios, comportamentos e lutas nos mostram seus modos de ser e viver e nos dão sua marca na história.

\section{THE NORMAL HEART: LIBERAÇÃO SEXUAL X CONTROLE NO CENÁRIO DA AIDS}

The Normal Heart (2014) inicia sua trajetória narrativa nos transportando para o ano de 1981, ao som do barulho das ondas estremecedoras e fortes do mar, ao mesmo tempo em que nos dá visualmente sua imensidão, embarcamos para um mundo subalterno e único das subjetividades gays, e ancoramos no cenário da Fire Island, reduto e espécie de paraíso gay, onde homens com seus corpos desnudos, fortes, jovens, musculosos e sensuais se refugiam, corpos que serão devastados posteriormente pela Aids. É nessa paisagem que acontecem inúmeras orgias sexuais, que nos deparamos com o grupo de gays protagonistas da história. Um deles, Ned Weeks, inconformado com a conduta sexual que visualiza no lugar, acredita ser impossível encontrar o amor em meio a tanto sexo. E é também nesse cenário que começam a aparecer os primeiros sintomas da ainda desconhecida epidemia devastadora da Aids.

Ao retornar à Nova York, Ned lê um artigo do The New York Times escrito por uma médica (Emma) e cujo título é "Câncer raro é diagnosticado em 41 homossexuais", o personagem fica preocupado e vai ao encontro de Emma. O filme mostra a figura da médica pioneira na dedicação ao "câncer gay", que ao cuidar dos pacientes infectados acaba por revelar um discurso médicomoralizante. Emma tenta ajudar no tratamento e prevenção da doença que assola os homossexuais masculinos, ao mesmo tempo em que propaga um caráter normalizador de contenção da sexualidade. Por acreditar que a praga atinge somente homens gays, a doutora deseja que Ned convença os grupos e a comunidade gay, sobre a qual ele tem um certo prestígio, a pararem de fazer sexo, tendo em vista suas desconfianças de transmissão do denomidado "cancêr gay" por vias sexuais.

É nessa direção que em paralelo com a realidade fílmica, Weeks (2013) alerta para um cenário no qual o fato dos primeiros sujeitos diagnósticados com Aids serem homens homossexuais, assinalou e determinou os quadros de respostas a essa crise, causando também uma profunda e enraizada estigmatização dos indivíduos portadores da síndrome. A associação entre Aids e homossexualidade masculina fez dela não apenas mais uma doença dentro do catálogo do mundo da saúde, mas inaugurou um dispositivo de controle do corpo e de seus atos sexualizados. Os esforços de Emma e Ned ao longo da película no intuito de conter a sexualidade dos homens gays, conter o "ímpeto" dos atos sexuais, como forma de prevenção à doença, revela esse pensamento 
médico e social da época de culpabilização do sexo pela epidemia, como se o fantasma ou o inimigo não fosse a Aids e, sim, o sexo ou desejo homossexual desregrado.

A epidemia torna-se, além de fato biológico, uma construção social, tendo em vista que mesmo sendo uma doença viral, foi classificada enquanto doença sexualmente transmissível, assinalando o sexo e o aidético como culpados por sua promiscuidade, e a Aids como castigo ou vingança da natureza para os que subvertiam a ordem sexual, natural ou tradicional (WEEKS, 2013). A Aids instaura uma poderosa frente conservadora e contrária à revolução sexual antecedente e recente, ocorrida nos Estados Unidos nos anos 60 e 70, e que lutava pelo alargamento das formas de viver a sexualidade livremente para além da heterossexualidade sacramentada no casamento e do sexo por procriação. O "amor livre", homossexual e prazeroso do movimento de liberação sexual torna-se agora um amor letal, ilícito que conduzia os sujeitos à dor, à doença e à morte, instaurando um pânico sexual acompanhado de controle e estigma.

Esse modelo de prevenção da doença através do controle sobre os corpos, seus atos, afetos, desejos sexuais, é o que Pelúcio e Miskolci (2009) denominam de repatologização da sexualidade desviante do padrão heterossexual. De acordo com os autores, ao ser contruída enquanto DST (Doença Sexualmente Transmissível), a Aids se constituiu em uma espécie de retorno médicomoralizante dos excessos e ameaças advindas da revolução sexual, em suas palavras "Os discursos morais sobre o 'mal sexo' ganhavam uma roupagem científica, agora que a homossexualidade, sobretudo a masculina, podia ser repatologizada em outros termos através de uma doença que chegou a ser anunciada como "o câncer gay" (PELÚCIO; MISKOLCI, 2009, p.1).

A instauração da Aids enquanto fantasma assolador da sexualidade humana, pricipalmente do desejo homossexual, e como fonte para perseguir e controlar esse desejo foi criticada na película pela própria comunidade gay, insatisfeita com esse retrocesso pós-revolução sexual. Tal argumentação também foi utilizada pelo personagem Ned, que diz a Emma que a revolução sexual que vinha ocorrendo marcou uma abertura à desejos e sexualidades não-normativas, em suas palavras: Percebe que está falando de milhões de homens que escolheram a promiscuidade como sua principal agenda política? Como lida com isso?. Percebe-se no discuro do personagem que o sexo predomina enquanto dimensão promíscua e desregrada do humano mesmo no contexto pós revolução.

No decorrer da narrativa, o personagem decide aceitar os conselhos da médica e organiza uma reunião com a comunidade gay, na qual a Emma explica os casos e a letalidade da epidemia e pede para que a comunidade pare de fazer sexo por um tempo até que se descubra mais sobre a doença, seus modos de transmissão e tratamento, no entanto, a comunidade despreza essa perspectiva de contaminação e culpabilização através do sexo. 0 argumento dos personagens partícipes da comunidade é de que as pessoas terão medo de fazer sexo, e parar de fazê-lo significa para alguns a derrota da luta travada durante anos pela liberdade dos homossexuais, de fazer amor em todos os lugares, amar abertamente sem precisar se esconder ou se culpar, de forma que eles preferem viver o desejo, não enxergando-o como ameaçador ou mortal.

Nos dias de hoje, após os diversos avanços científicos a respeito da doença, é sabido que qualquer "categoria" de sujeito é passível de contrair Aids, o que está provocando uma mudança gradativa de paradigma da culpabilização do sujeito homossexual, no entanto, persiste o paradigma do sexo/sexualidade enquanto dispositivo ameçador. Nessa perspectiva, o que antes era chamado 
de "grupo de risco", personalizado nos sujeitos gays masculinos, passou a ser denominado segundo a nomenclatura "comportamento/atividade de risco" sinalizando a mudança de eixo que estigmatizava o grupo de homossexuais masculinos como categoria doente e reponsável pela catástrofe da síndrome aidética.

Contudo, mesmo com todos os esforços, a associação entre Aids e homossexualidade masculina ainda paira fortemente no imaginário sócio-cultural, de forma que a doença ainda é sinônimo do ser gay ou vice-versa. De acordo com Louro (2013, p.36) “O combate à doença também acarreta um deslocamento nos discursos a respeito da sexualidade - agora os discursos se dirigem menos às identidades e se concentram mais nas práticas sexuais (ao enfatizar, por exemplo, a prática do sexo seguro)". E ao deslocar a culpa do sujeito para o comportamento, configura-se uma pequena isenção do sujeito, e uma continuação da percepção do sexo/sexualidade como algo potencialmente perigoso e danoso. Um discurso culpabilizador e moralizante recai ainda sobre o sexo, que se constitui em risco, principalmente nas relações que não procriam e que buscam o prazer.

\section{CORPO, ABJEÇÃO E IDENTIDADE HOMOSSEXUAL}

Weeks (2013) ao iniciar seu texto intitulado "o corpo e a sexualidade" nos relembra que a Aids é responsável por devastar o corpo, e nos fornece uma imagem, que segundo ele tem nos assombrado nos últimos tempos, a imagem de corpos aidéticos, macilentos, magros, pálidos e arruinados, corpos que contrastam ferozmente com a celebração de corpos sadios, harmônicos e joviais de nossa época, corpos que carregam o castigo pelo desregramento e "perversidade" sexual.

Quando nos reportamos à narrativa fílmica aqui analisada, percebemos um contraste extremo dos corpos antes e depois de contraírem a doença. Corpos belos, musculosos e jovens viram ruínas, perdem peso, sucumbem de dor, tornam-se corpos quase mortos, suspiros de vida, literalmente devastados pela síndrome, como é possível visualizar nas Figuras 1 e 2 abaixo:

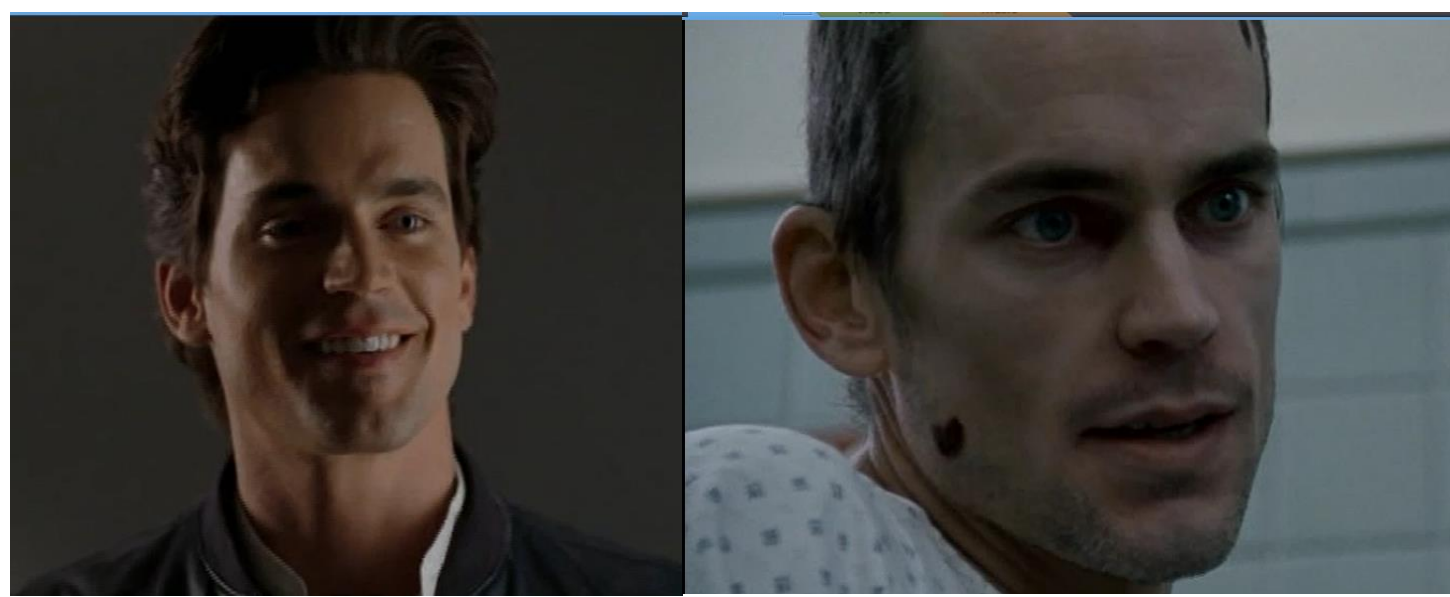

Figuras 1 e 2: Antes e depois de Felix - A decadência do corpo aidético

Fonte: Cenas do filme The Normal Heart (Ryan Murphy, 2014).

Felix, que ao longo da trama torna-se o amante do personagem Ned, se descobre com Aids, e seu corpo e beleza definham seus últimos fios e suspiros de vida, como podemos ver nas Figuras acima, a única coisa que parece continuar viva são seus olhos azuis. Os corpos simplesmente entram 
em colapso ao terem seu sistema imunológico arruinado e destruído através de um vírus misterioso que se alastra rapidamente pela comunidade gay e deixa suas marcas nos corpos, que na maioria dos casos, não sobrevivem. Uma verdadeira epidemia que vai minando vida por vida dos garotos e seus amantes.

Os corpos aidéticos representados no filme possuem algumas semelhanças com a situação na vida real, são corpos fracos, febris, que suam e são acometidos de mal-estares. Além disso, os personagens sangram, secretam líquidos, fluídos, tem colapsos, morrem rapidamente, e possuem ainda hematomas e feridas pelo corpo inteiro, que marcam inevitavelmente sua condição de saúde e também sua condição sexual/moral.

O "câncer gay" representado na película, diferentemente da realidade, é marcado na pele, como estigma. Tal estratégia fílmica pode ser lida como forma de concretizar o estigma da sexualidade e da Aids sofrida pelo sujeito gay da época de forma concreta e visível no corpo. As manchas e feridas que continuam a crescer e se espalhar pelo corpo dos personagens infectados são as marcas do nojo, da abjeção, o castigo pela ousadia de subverter a lógica moral e sexual vigente.

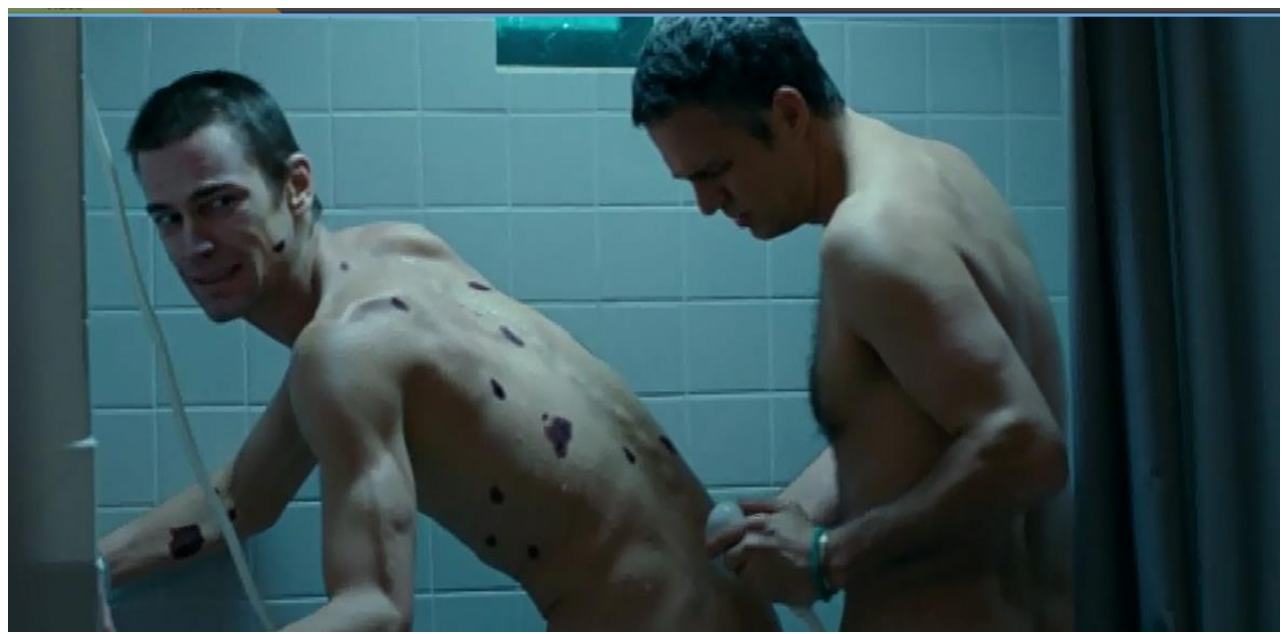

Figura 3: O castigo visível e letal da subversão sexual

Fonte: Cenas do filme The Normal Heart (Ryan Murphy, 2014).

A doença tem uma letalidade incrível e começa a devastar a população gay da cidade, marcando seus portadores, impossibilitando que os sujeitos que a contraíram passem despercebidos aos olhos da sociedade, uma marca corporal que se transforma em estigma social. Compreendendo estigma enquanto marca/signo social que inferioriza determinado grupo ou pessoa que desvia da normatividade, tem-se que:

O termo estigma foi cunhado na Grécia antiga, para designar marcas físicas produzidas artificialmente no corpo de uma pessoa (com cortes ou ferro em brasa), para sinalizar o status moral inferior dela, indicando que se tratava de uma pessoa moralmente manchada (OMOTE, 2004, p.293).

No caso dos corpos aidéticos mostrados no filme, o significado de estigma não se distancia de sua origem trazida pelo autor acima destacado, e se articula a uma conjuntura de descrédito, funcionando simbolicamente como uma mancha que aponta como moralmente inferior um grupo 
ou pessoa infratora que destoa do aceitável socialmente, é a marca da "degeneração sexual", fortificando a abjeção.

A problemática da abjeção se fez presente de forma forte ao longo da história da sexualidade e de seus desvios, e se intensificou consideravelmente com o advento da Aids, que provocou pânico, classificando seu portador como "[...] poluidor ou impuro, a ponto de ser o contato com isso temido como contaminador e nauseante. A injúria classifica alguém como 'poluidora', como alguém de quem você quer distância por temer ser contaminado" (MISKOLCl, 2012, p.40).

$\mathrm{Na}$ sequência cenográfica abaixo, percebemos que era extamente dentro de uma perspectiva poluidora, abjeta e marcada social e corporalmente que os personagens da película infectados pela doença se encontravam:
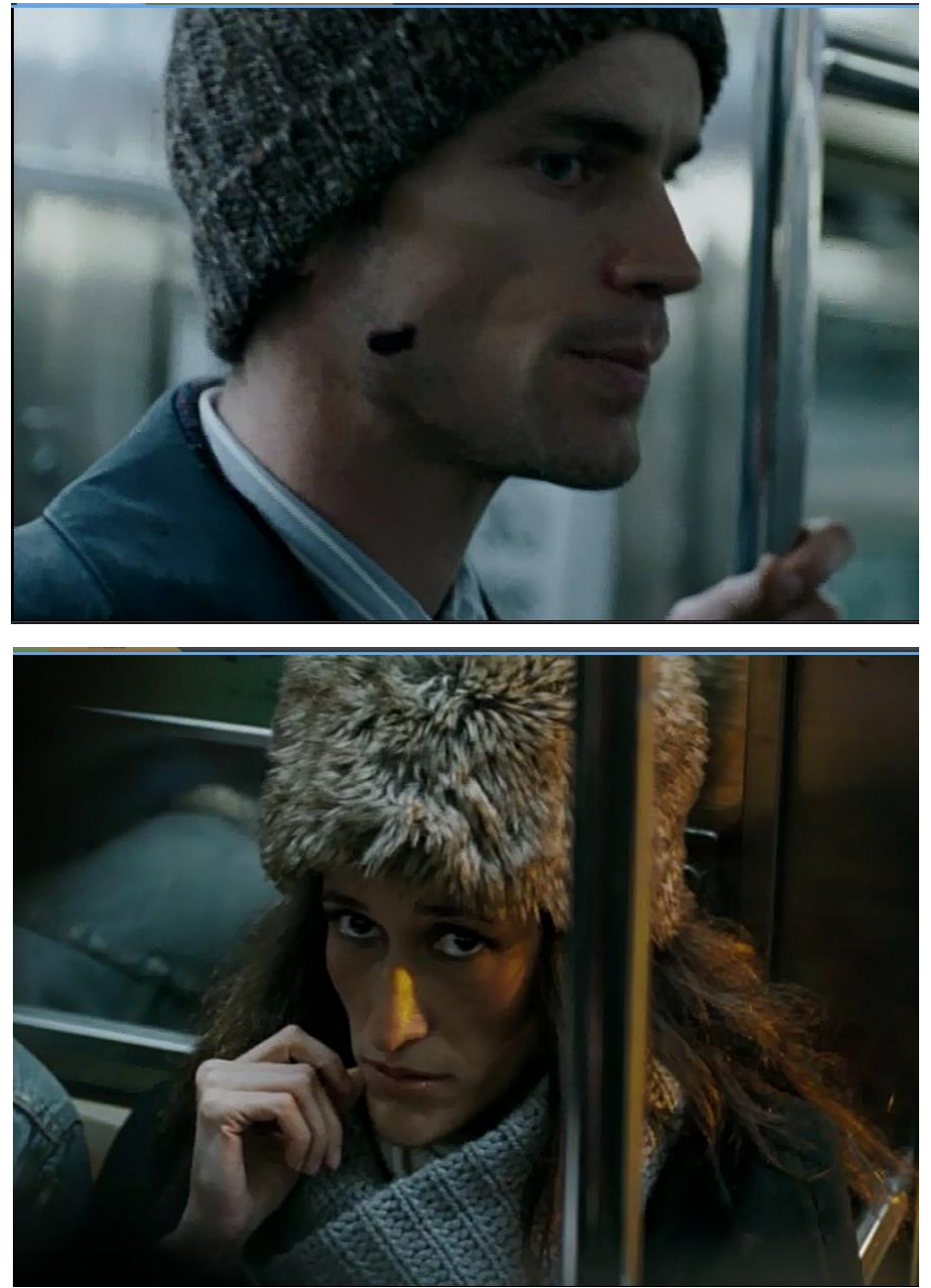

Figura 4: Olhos da abjeção

Fonte: Cenas do filme The Normal Heart (Ryan Murphy, 2014).

Na cena, Felix está marcado no corpo pelo estigma personificado através das feridas como portador do "câncer gay", e, por mais que as tente esconder por meio das roupas, elas aparecem em todas as partes de seu corpo. Enquanto se locomove no metrô, ele tem que lidar com olhares amedrontados das pessoas, que o configuram enquanto ser abjeto, poluidor e contaminador, marcado socialmente como moralmente trangressor por se relacionar com outros homens, seus olhos portam a vergonha de tal condição irremediavelmente tatuada no corpo por meio das 
manchas. À sua frente, uma moça sentada o olha com uma mistura de pena e medo, horrorizada com um sujeito que não se encaixa nos códigos morais, sexuais e corporais ditados, e que parece estar sendo "punido" por sua ousadia em romper com tais códigos e por viver uma sexualidade "impura" sem o regramento instituído, uma "punição" configurada corporalmente através da doença e de suas chagas, e socialmente por meio da abjeção, exlusão, repugnância personificados no olhar temeroso da moça no metrô para com um "objeto" contaminador.

Segundo Miskolci (2012) a experiência da abjeção consiste em ser repugnado, temido, negado, pois sua existência corporal é um perigo ao perturbar a homogeneidade, a ordem, as identidades. $E$, nessa direção, a Aids constituiu-se enquanto catalisador da abjeção e do julgamento do desejo homoerótico, o que contribuiu e reforçou o pânico sexual da década de 80 , bem como condenou social e moralmente o sujeito homossexual. Nesse caso, o aidético era a própria encarnação desse fantasma perturbador que ameaçava a sociedade, que por sua vez, lhe impunha seu código moral, seu julgamento, sua classificação enquanto sujeito poluído.

Esse cenário de abjeção do corpo aidético se faz presente em toda a narrativa cinematográfica, desde a recusa dos hospitais em receber sujeitos infectados, passando pelas dificuldades em conseguir ajuda para os afetados, e chegando ao quadro de recusa do governo em auxiliar a conter e superar a epidemia. A película visibiliza inúmeras tentativas dos personagens e organizações para conseguir apoio financeiro de representantes do Estado, no entanto, ao saberem que a doença, de acordo com a narrativa, era uma condição restrita aos homossexuais e por culpabilizarem suas práticas sexuais como impuras, desmedidas, censuradas e imorais, sempre negavam o apoio. Tal cenário de descaso é perceptível na narração fílmica e materializado na fala do personagem Tommy, que indignado por estar realizando mais uma cerimônia fúnebre e pela perda de mais um jovem amigo, indaga: Porque nos deixam morrer? Por que ninguém está nos ajudando? Aqui está a verdade, a resposta é que eles simplesmente não gostam de nós. O pronome "eles" na frase pode ser entendido como a sociedade em geral e o Estado que ignora a epidemia e as sucessivas mortes.

Na contramão disso, é preciso destacar que esse contexto de abjeção também contribuiu para aflorar atitudes e movimentos contrários à negação e descaso relegado aos sujeitos gays e aidéticos. Na película se assiste à emergência de uma articulação da comunidade gay contra o fantasma da Aids, associações e organizações se formam em prol dos infectados e com o intuito de arrecadar fundos, tendo como cenário a cidade de Nova York. Logo, ao mesmo tempo em que se presencia um retraimento da revolução sexual e um quadro de abjeção generalizada, se observa também uma reposta da sociedade americana ao estigma, através de movimentos como o ACT-UP e o Queer Nation. Essas formas de resistência, principalmente concretizadas com o Queer Nation, pressupunham segundo Miskolci (2012) uma materialização da ideia de que uma nação foi rejeitada, tida como abjeta, impura, contaminada, relegada ao desprezo por ser uma "nação bicha".

Dessa forma, essa conjuntura de resistência à abjeção para com o aidético e homossexual contribuiu fortemente para a emergência e cristalização do movimento político e teórico queer, que surge extamente na década de 80 nos Estados Unidos, tomando emprestado o termo do Queer Nation. Ao problematizar e deslocar conceitos de identidade e sexualidade, o movimento almeja colocar o "anormal", a "bicha" no epicentro, tentando retirá-lo da clandestinidade científica, social, sexual e moral. 
Por fim, é preciso atentar para o fato de que esse cenário problemático da Aids discutido neste texto sob à luz do filme, o descaso para com a epidemia, a estigmatização e abjeção do sujeito gay, bem como a fortificação de uma política a partir do pânico sexual só foram possíveis pela existência de uma identidade, de uma categoria, de um tipo distintivo de ser humano que emerge no século XIX: o homossexual,

[...] esse novo zelo categorizador e definidor, ao redor do século XIX, constitui uma mudança tão significativa na definição pública e privada da homossexualidade quanto a emergência de uma política gay e lésbica aberta e desafiadora nas cidades americanas, em fins dos anos 1960 e início dos anos 1970 (WEEKS, 2013, p.65).

A fixação e demarcação identitária homossexual constrói uma política de identidade, que é responsável por determinar uma fronteira ou território e catalogar os sujeitos em tipologias diferentes, fundando uma categoria sociológica, científica, psicológica e sexológica cujos efeitos são visíveis nas práticas e normas médicas e legais desde a época da epidemia reverberando até os dias de hoje. $E$, ao mesmo tempo, tal distinção, oferece um sentimento de unidade, pertencimento e localização dentro da sociedade, além de proporcionar ao sujeito assumir um posicionamento político dentro da organização social dominante (WEEKS, 2013). Esse paradoxo da identidade, é colocado em tela no filme, que tensiona a criação de uma comunidade gay em resposta à epidemia, e as consequências do estabelecimento de uma identidade social em termos da abjeção corporal e moral.

\section{CONSIDERAÇÕES FINAIS}

The Normal Heart é um filme intenso, sensível e político, que ao unir amor, desejo, sexualidade e morte no drama existencial dos personagens, nos fornece histórias de amor, lágrimas, funerais, preconceitos, abjeção, lutas, subalternidade, e, sobretudo, nos dá a presença e a experiência do corpo sexuado que se opõe aos desejos da sexualidade normativa.

Ao dar visibilidade a vidas que se interrompem, uma a uma, e vão virando cinzas, nos possibilita pensar na paisagem política, sexual, corporal e moral característica do surgimento e emergência da Aids ou "câncer gay". Nessa direção, a película contribui para pensar e refletir sobre as relações entre corpo, abjeção, controle e liberação sexual a partir de um dos grandes marcos da história da sexualidade moderna, considerando a lógica dos sujeitos infectados, do governo e da dimensão médica-moral.

Por possibilitar o contato com esse panorama, despertando reflexões e questões, o filme deve ser visitado, apreciado, problematizado e analisado por aqueles que se interessam pelas dimensões do corpo e da sexualidade humana, proliferando discussões sobre essa "história", questionando-a e percebendo sua marcada importância para o cenário atual da sexualidade, do corpo e da abjeção.

\section{REFERÊNCIAS BIBLIOGRÁFICAS}

1. LIMA NETO, A. A.; NÓBREGA, T. P. Corpo, Cinema e Educação: Cartografias do Ver. Holos, ano 30, v.5, p.81-96, 2014. 
2. LOURO, G. L. Um corpo estranho: Ensaios sobre sexualidade e teoria queer. 2.ed. Belo Horizonte: Autêntica Editora, 2013.

3. MISKOLCI, R. Teoria Queer: um aprendizado pelas diferenças. São Paulo: Autêntica, 2012.

4. NAZARIO, L. O outro cinema. Aletria, v.16, p.94-109, jul-dez. 2005.

5. OMOTE, S. Estigma no tempo da inclusão. Rev. Bras. Ed. Esp., Marília, Set.-Dez. 2004, v.10, n.3, p.287-308.

6. PELÚCIO, L.; MISKOLCl, R. A prevenção do desvio: o dispositivo da aids e a repatologização das sexualidades disidentes. Sexualidad, Salud y Sociedad - Revista Latinoamericana, n.1, p.125157, 2009.

7. WEEKS, Jeffrey. O corpo e a sexualidade. In: LOURO, Guacira Lopes (Orgs.). O corpo educado: pedagogias da sexualidade. 2.ed. Belo Horizonte: Autêntica, 2013. 